\title{
Teaching and Examination Process of Some University Courses before vs during the Corona Crisis
}

\section{Vesna Dimitrievska RISTOVSKA, Emil STANKOV, Petar SEKULOSKI}

Faculty of Computer Science and Engineering, Ss. Cyril and Methodius University st. Rugjer Boshkovikj 16 Skopje, Macedonia

e-mail:vesna.dimitrievska.ristovska@finki.ukim.mk,emil.stankov@finki.ukim.mk, petar.sekuloski@finki.ukim.mk

\begin{abstract}
The newly emerged corona crisis in our country, but also much broader - on the entire planet, caused by the pandemic scale of COVID-19 virus, dictated the need for adjustment of the teaching and examination process of many university courses. At our institution, Faculty of Computer Science and Engineering (FCSE) in Skopje, starting from March 17, 2020, until today (March 2021), classes and exams are completely realized through distance learning systems, i.e. using the BigBlueButton video conferencing system, implemented in the Courses and Exams student services - the official FCSE websites on the Moodle e-learning platform.

For all faculty courses, lectures, auditory and laboratory exercises, colloquia and exams, all take place via a video conferencing system for distance education.

In this paper we present a comparative analysis of the conduction of some courses at FCSE in classical conditions, as opposed to the conditions with distance education. We have considered the analysis mainly from the aspect of the approach to teaching, as well as from the aspect of exam conduction and achieved exam results. The analysis of those aspects leads us to conclusions about several positive and negative sides that we noticed in distance education compared to the classical conditions of classes and exams. Our findings also may apply on the organization of online contests, especially in informatics.
\end{abstract}

Keywords. distance education, online classes, online exams, university subjects, corona crisis, BigBlueButton (BBB), Calculus, survey.

\section{Introduction}

In this paper we review and compare some aspects of the teaching process as well as the exam results for several courses at our institution, Faculty of Computer Science and Engineering (FCSE), at the Ss. Cyril and Methodius University in Skopje, in the period before the corona crisis, as opposed to the first year of the corona crisis. Elec- 
tronic services, such as announcements regarding classes and exams, exam registration, exam surveys, submission of solutions to assignments, projects, etc., as well as exams conduction, have been used at FCSE for many years. Experiences with the usage of electronic services have made it much easier to bridge the interruption of the classical teaching process caused by the corona crisis. The teaching program of most subjects at FCSE includes theoretical lectures, auditory and laboratory exercises. In regular circumstances, the lectures and auditory exercises typically take place in the classroom, using a whiteboard and a video beam. The emerging corona crisis in our country, and much broader - on the entire planet, caused by the pandemic of the virus causing the COVID-19 disease, dictated the need for adjustment of the teaching and examination process of many university courses.

The World Health Organization (WHO) declared a pandemic on March 11, 2020, and less than a week after that date, i.e. as of March 17, 2020, until today (March 2021), the classes and exams at FCSE are being conducted through distance learning systems completely. This is done using the BigBlueButton (BBB) video conferencing system, implemented in the Courses and Exams student services, i.e. the official FCSE websites on the Moodle e-learning platform.

Distance learning is not a modern phenomenon. In the twentieth century, distance learning includes technologies such as radio and television, but without mass usage. As the technology was advancing in the new computer era, this way of learning emerged to new multimedia technologies (Pregowska et al., 2021). Although, many of the educational programs partially included some distance learning methods, the main challenge came with the COVID-19 pandemic (Chan et al., 2021).

Section 2 discusses the related work on distance education throughout the ongoing pandemic period, on different educational levels. In the following sections we present our comparison of the teaching process and the results of the exams for several courses at FCSE.

\section{Related Work}

Asgari et al. (2021) conducted an observational study at California State University, Long Beach (one of the largest and most diverse four-year university in the U.S.) to enhance engineering online education during the pandemic. From six engineering departments, a total of 110 faculty members and 627 students answered questions in their surveys, to highlight the challenges they experienced during the online instruction in Spring 2020. Their results show different issues that negatively influenced the online engineering education: for example, more than half of the students indicated lack of engagement in class, difficulty in maintaining their focus and Zoom fatigue after attending multiple online sessions. The authors recommend strategies for educational stakeholders to fill the tools and technology gap and improve online engineering education.

Dhawan (2020) focuses on the importance of online learning and the Strengths, Weaknesses, Opportunities \& Challenges (SWOC) analysis of e-learning modes in 
the time of crisis. This article observes the growth of EdTech Start-ups during the time of pandemic and natural disasters and suggests how to deal with challenges associated with online learning.

Ballova Mikuskova and Veresova (2020) focus on distance education implemented in primary and secondary schools in Slovakia during the COVID-19 pandemic. They analyze distance education from teachers' point of view, particularly from the aspect of the connection between the teacher's previous experience, perception and the management of the educational process in the pandemic period.

\section{Comparative Analysis of Regular Classes Vs Classes during the Corona Crisis}

Most of the subjects at FCSE involve classes, which consist of lectures, auditory and laboratory exercises. The classical way of conducting the lectures and exercises (until the onset of the corona pandemic) was in the classroom, using a whiteboard and a video beam. However, as explained previously, due to the COVID-19 pandemic, the process had to be adjusted to the newly emerged circumstances.

During the corona crisis, for all courses at the faculty, distance education realized through lectures, auditory and laboratory exercises, as well as colloquia and exams, took place through the BigBlueButton (BBB) video conferencing system, implemented in the Courses and Exams student services, i.e. the official FCSE websites on the Moodle e-learning platform.

In each of the following subsections we briefly describe the classical teaching approaches for the theoretical lectures, auditory and laboratory exercises, and then elaborate on the adjusted online approaches that were implemented with the outbreak of the pandemic.

\subsection{Theoretical Lectures}

In the classical theoretical lectures for the courses at FCSE, the teacher typically explains the planned topic, uses video-beam presentations for the lesson, which show definitions, algorithms, program sequences, schemes, theorems, proofs, properties, as well as tasks from the material. Depending on the material under consideration, the teacher writes solutions to problems in detail on the whiteboard or on his computer while sharing the computer screen using a video beam, sketches graphs or diagrams, derives proofs of theorems, etc.

At the very beginning of the corona period, several questions arose about the manner of teaching, for which a decision had to be made as soon as possible, in order to continue with the interrupted educational process:

1. Should the lectures be recorded, or should each lecture be conducted online only, without recording, at a time provided in the faculty schedule of classes? 
2. If the lectures are recorded, should it be done beforehand, and not at the class itself, in order to prepare a better and cleaner recording, on which there would be no possible questions from students?

According to the strategy adopted by the Teaching/Scientific Council of the faculty, the details of the conduction of online classes for each course were left to the estimate of the course teachers. Thus, there were differences in the teaching approaches adopted in different courses.

\subsection{Auditory Exercises}

The classical teaching approach for the auditory exercises of most subjects at FCSE is such that the teaching assistant explains and writes the solutions of the topic's tasks on a whiteboard or on his computer - while sharing the computer screen using a video beam, sketches graphs, tables, ideas, etc. Very often, a parallel display of the material on a video beam is used during the classes, so that the students can have a better insight into the textual description of the tasks.

\subsection{Laboratory Exercises}

On the other hand, the regular laboratory exercises involved solving basic and advanced tasks related to the subject's material in some appropriate software environment / programming language, such as $\mathrm{C}++$, Python, $\mathrm{R}$, GeoGebra, Wolfram Mathematica, etc. Until two years ago, the presence of students at the laboratory exercises was mandatory, but for the last two years, until the onset of the corona pandemic, these exercises were mostly consultative. Namely, every week a manual for the exercise was published for the students, with appropriately explained commands and solved tasks, but also tasks assigned for individual work of the student intended to prepare him / her for the lab exam. The student had the possibility to attend the laboratory and ask the responsible teaching assistant about the planned tasks, but he / she could also work out the planned material for the laboratory exercise at home.

With the outbreak of the pandemic and the caused interruption of classes, similar issues regarding the way of continuation of the educational process arose to those described for the theoretical lectures:

1. Should the auditory and lab exercises be conducted through online lessons using a webcam or by sharing the computer screen and solving tasks directly in a software environment, or on a piece of paper with a pen, or a digital board, or using pdf materials and additional oral explanation?

2. Should the auditory and lab exercises be conducted using pre-prepared videos, which could be used during the scheduled terms for the auditory and lab exercises, so that the online classes would be used only for clarification of some of the details, or only some of the tasks according to the students' needs? 
Once again, according to the official strategy of the faculty, the decision on the approach to classes realization was left to the teaching stuff of each individual course, and thus, different approaches were taken for different courses.

In the next section we analyze the exams conduction for some courses at FCSE: the classical approach (before the corona crisis), as opposed to the online approach implemented during the corona crisis.

\section{Comparative Analysis of Regular Exams Vs Exams during the Corona Crisis}

\subsection{Exams before the Corona Crisis}

In regular circumstances, before the outbreak of the pandemic, the exams for most courses at FCSE were conducted in a classroom or amphitheater, so that students wrote answers to questions and solved tasks on paper. Exception was the lab exam, which was taken in the laboratory, on a computer, by solving tasks in the appropriate programming language.

\subsection{Exams during the Corona Crisis}

The first summer midterms, which before the corona crisis would normally take place in April, in the summer semester of 2019/2020 were held only for some courses, the socalled "pilot courses" - mostly with a smaller number of students.

The following three major exam sessions: June, September and January, as well as the two partial exams (colloquia) in the winter semester of 2020/2021 were held completely online, usually using two cameras, through the BigBlueButton (BBB) system. One camera was from the student's computer (the student was required to share the screen for constant insight into his / her work), and the second was a mobile phone or web camera, positioned to the right of the student, so that the student, his / her desk and the computer he / she is working on could be followed closely. Any materials other than those permitted for the course were prohibited during the examination. The use of social networks or communication software was also strictly forbidden.

For students who would not have the appropriate technical conditions for taking online exams from home (adequate hardware equipment and stable Internet connection), the faculty provided the option of taking exams with physical presence. Such students were required to register by filling a survey in a timely manner prior to the exam session, and all exams in that session were to be taken in person. For the needs of these exams with physical presence, in each exam session, an appropriate, large enough computer laboratory was prepared in which a safe distance was provided between the students and all recommendations and measures for protection of students' health were respected. Furthermore, a high-quality webcam was installed in the laboratory in order 
to provide a constant supervision during the exam. For these students, as well as for the other students present at the exam, the same rules for taking the exam applied.

For each online exam, students are required to connect to an assigned BBB session. Typically, about 20 students are assigned per BBB session. All activities are being recorded throughout the entire BBB session. Before the start of the exam, each student is identified with his / her student ID or other personal identification document. If the student uses one or more sheets of paper as an aid in solving the exam questions / tasks, he / she must show it on camera before the beginning of the exam so that the teacher can be assured that it is empty. Each teacher follows all students with video and audio signal during the exam, and on the teacher's screen there is a list of names of all students currently present at the BBB session. If necessary, the teacher can zoom in on a student's recording to check if there is a suspicious activity. If a student has a question, he / she can ask it in written (electronic) form in the public chat of the BBB session.

All course teachers, course teaching assistants, and additional teaching stuff responsible for the exam supervision, are connected to a viber group for faster mutual coordination on exam questions and other exam issues.

\subsection{Problems Part of the Exams during the Corona Crisis}

In the June exam session, the Problems part of the exam for most of the courses at FCSE was realized directly in an appropriate software environment, except for the Calculus 1 and Calculus 2 courses, where students were required to solve the tasks on paper using a pen. The duration of this part was 2.5 hours, and at the end of the exam the students were obliged to take photo(s) of the solutions using a mobile phone and attach them at the appropriate assignment on the Moodle system.

From the September session onwards, the Problems part in Calculus 1 and Calculus 2 was conducted as follows: the student solves the tasks on paper with a pen, and then writes the solutions in a math formula editor, based on TEX-commands, which is built-in in the Moodle e-learning platform. The duration of the exam was increased to 3 hours in order to enable students enough time for typing the solutions in the editor. Prior to the September session, the teaching assistants had prepared a tutorial for the students, with ready-made examples to illustrate how to write the basic required formulas in the editor.

\subsection{Theoretical Part of the Exams during the Corona Crisis}

The Theory part of the exam, took place online, through a Moodle quiz which contained different types of questions: some of the questions were single or multiple choice, for some of them - a short answer had to be entered (for example - a number or a letter), and for some - the student had to write a definition, property, proof, etc.

Depending on the teacher's findings, if necessary, some of the students were called for additional oral interrogation in front of the camera in order to assess their knowledge more precisely. 


\subsection{Lab Exams during the Corona Crisis}

This part of the exam took place on a computer, with two cameras on, while the student solved several tasks in some appropriate programming language.

\section{Case Study: Comparison of Exam Results from Some Courses before VS during the Corona Crisis}

\subsection{Calculus 1 - Fall/Winter (October to February) \\ Semester 2019/2020 and 2020/2021}

Table (see Fig.1) presents an analysis of the results from the partial exams and the January exam session, for the Calculus 1 course, in the winter semesters of the academic years 2019/2020 and 2020/2021. From the data given in Fig. 1, we can conclude that there is an increasing number of students that pass the Calculus 1 course through partial exams during

\begin{tabular}{|c|c|c|}
\hline Academic year & $2019 / 2020$ & $2020 / 2021$ \\
\hline Number of students that pass Theory part on partial exams & $51 / 202$ & $68 / 104$ \\
\hline Percentage of students pass Theory part on partial exams & 25.25 & 48.57 \\
\hline Number of students that pass Problems part on partial exams & $42 / 188$ & $44 / 90$ \\
\hline Percentage of students pass Problems part on partial exams & 22.34 & 48.89 \\
\hline Number of students that pass the exam on partial exams & 36 & 40 \\
\hline Percentage of students that pass the exam on partial exams & 19.15 & 44.44 \\
\hline $6(\mathrm{E})$ & 11 & 15 \\
\hline 7 (D) & 3 & 8 \\
\hline $8(C)$ & 10 & 7 \\
\hline 9 (B) & 10 & 5 \\
\hline 10 (A) & 2 & 5 \\
\hline Number of students that pass Theory part in January session & $51 / 121$ & $22 / 33$ \\
\hline Percentage of students pass Theory part in January session & 42.15 & 66.67 \\
\hline Number of students that pass Problems part in January session & $39 / 114$ & $25 / 46$ \\
\hline Percentage of students pass Problems part in January session & 34.21 & 54.35 \\
\hline Number of students that pass the exam in January session & 31 & 11 \\
\hline Percentage of students that pass the exam in January session & 27.19 & 33.33 \\
\hline $6(\mathrm{E})$ & 16 & 7 \\
\hline 7 (D) & 8 & 3 \\
\hline $8(C)$ & 5 & 0 \\
\hline 9 (B) & 2 & 0 \\
\hline $10(\mathrm{~A})$ & 0 & 1 \\
\hline $\begin{array}{l}\text { Total \# students that pass the exam (part. Exams + January } \\
\text { session) }\end{array}$ & $67 / 239$ & $51 / 112$ \\
\hline $\begin{array}{l}\text { Total percentage of students that pass the exam (part. Exams + } \\
\text { January session) }\end{array}$ & 28.03 & 45.54 \\
\hline
\end{tabular}

Fig. 1. Analysis of partial exams and January exam results in 2019/2020 and 2020/2021 (online). 
online examination in $2020 / 2021$, from $19.15 \%$ to $44.44 \%$. For the number of students that pass the exam in January, we can say that there is no significant increase. Also, from Fig. 2 , we can say that there is an increase in the number of students that achieved minimum points for passing the exam for the different exam parts during online examination.

The distribution of grades in percent is shown in Fig. 3. We can say that there is an increase in the percentage of the grades $10(A), 6(\mathrm{E})$, and 7 (D), and decrease of the grades $8(\mathrm{C})$ and $9(\mathrm{~B})$.

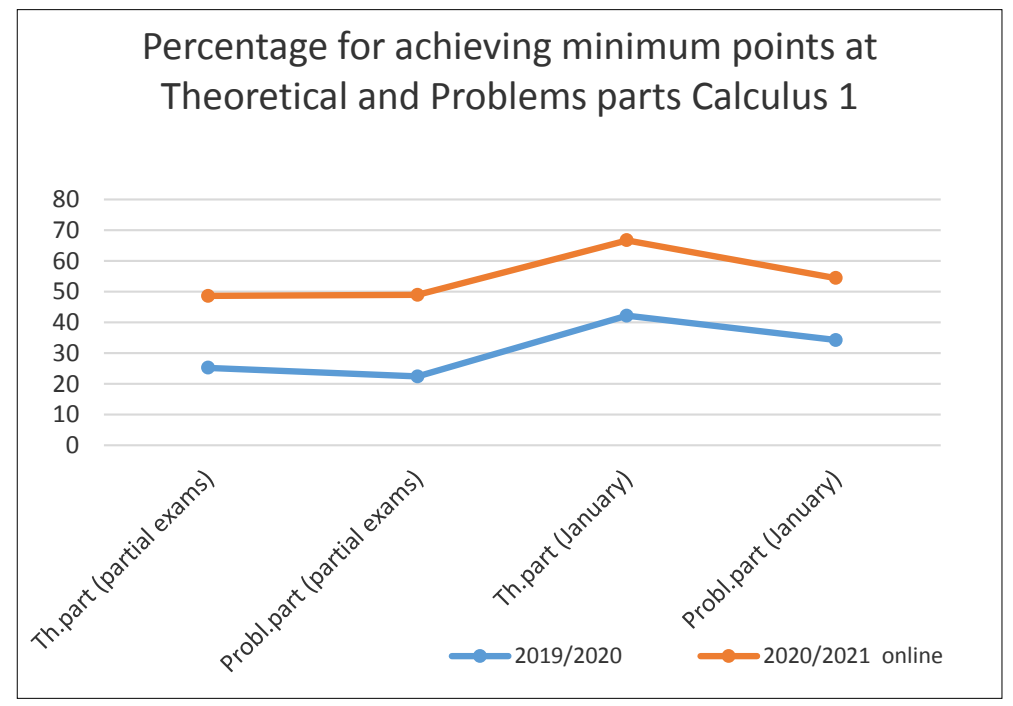

Fig. 2. Percentage of students that achieved minimum points on the different exam parts for Calculus 1 .

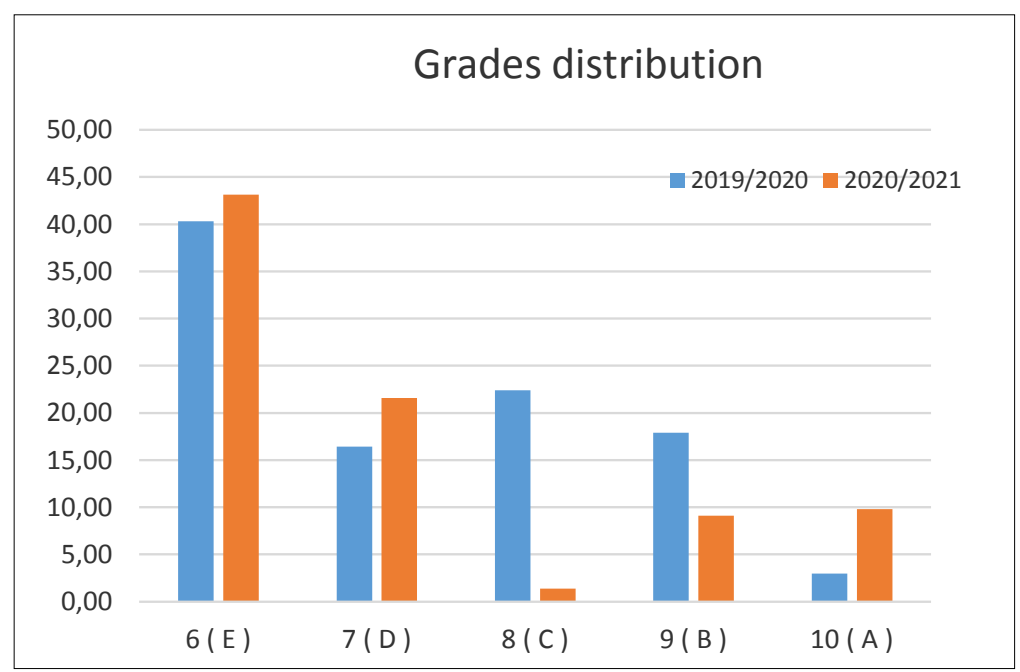

Fig. 3. Grades distribution for Calculus 1. 
5.2. Comparing Exam Results:

Business Statistics, Calculus 1, Calculus and Calculus 2

In Fig. 4 and Fig. 5, it is obvious that the percentage of students that pass the course Calculus 2 through partial exams in 2019/2020 is larger than the other given percentages. The reason for this can be the new program that was accredited that year. All the students enrolled in that course were students that are enrolled in Calculus 2 for the first time.

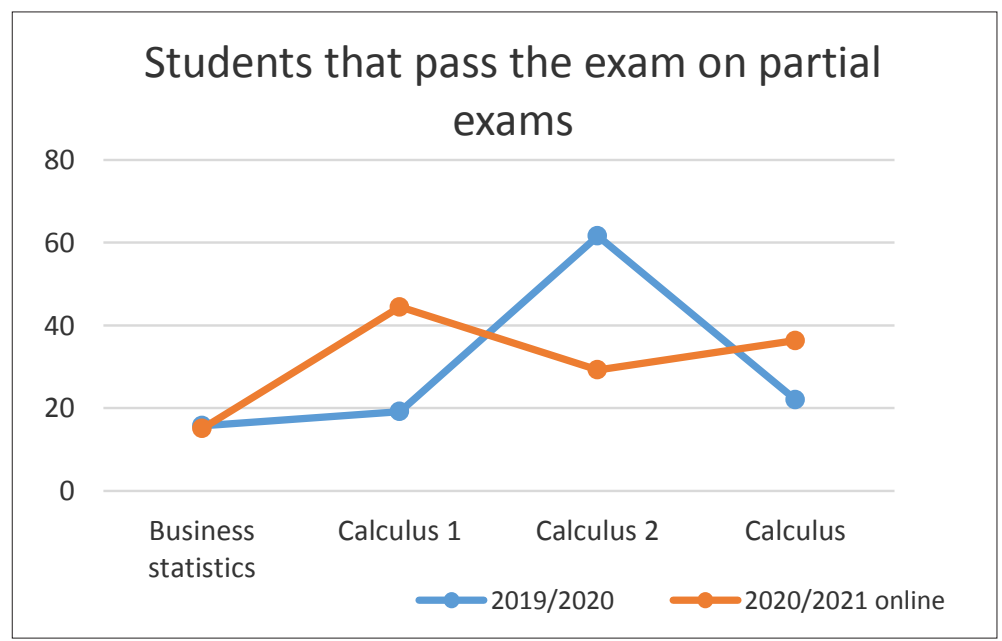

Fig. 4. Percentage of students that pass the partial exams for different courses.

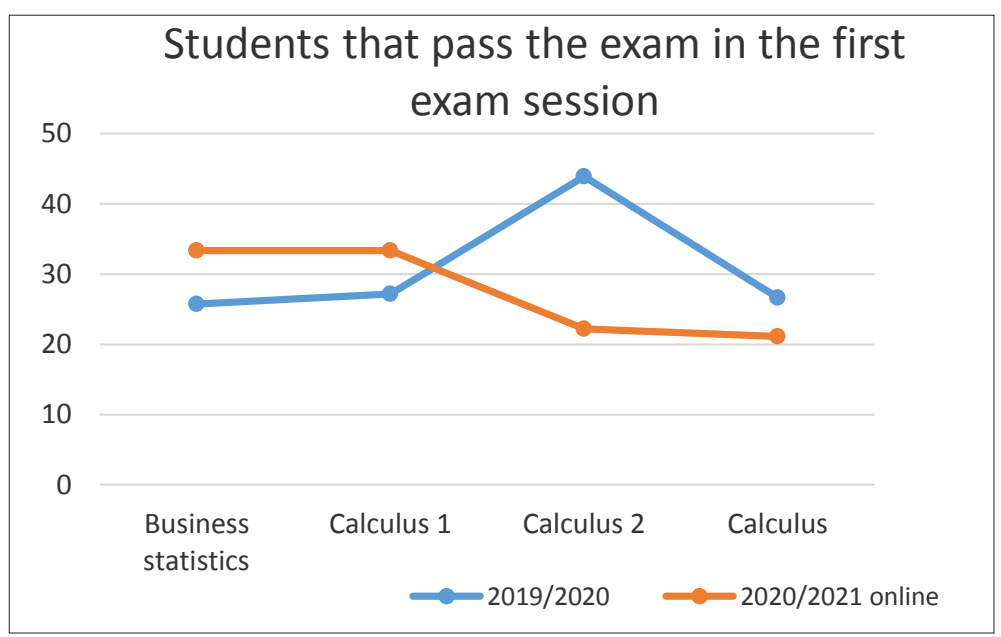

Fig. 5. Percentage of students that pass the first exam for different courses. 


\section{A Survey for the Online Classes during The Corona Crisis}

For the purpose of this paper we conducted a survey on the online practices in teaching and learning for the course Calculus 1 . The survey was taken by students that are enrolled in Calculus 1 in the academic year 2020/2021 (during the corona crisis). The questionnaire was composed of 8 questions that would detect advantages and disadvantages of the learning process. The questions were:

1. How satisfied are you with the online classes (theoretical lectures and auditory exercises):
a. Very satisfied.
b. Poorly satisfied.
c. Neutral.
d. Unsatisfied.
e. Very unsatisfied.

2. If you have noticed, please list at least one positive side of online classes that you think is important for mastering the material and passing the exam.

3. Please, if you have noticed, list some disadvantages of the online classes.

4. Please, if you have noticed, list some disadvantages of the online exams.

5. During the online lectures, the quality of the audio signal was:
a. Very good.
b. Good enough.
c. Good, with little noise or interference.
d. Bad.
e. Very bad, barely understandable.

6. During the online auditory exercises, the quality of the audio signal was:
a. Very good.
b. Good enough.
c. Good, with little noise or interference.
d. Bad.
e. Very bad, barely understandable.

7. During the online auditory exercises, the quality of the video signal was:
a. Very good.
b. Good enough.
c. Good, with little noise or interference.
d. Bad.
e. Very bad, barely understandable.

8. If, when using a recorded material from this course, you come across an obscure part, then you seek help from:
a. A colleague.
b. A friend.
c. A professor. 
d. A teaching assistant.

e. By sending message via e-mail to a professor/teaching assistant.

f. In the scheduled online office hours of the course's teaching stuff.

g. A book (hard copy).

h. Other online resources on the Internet.

From the results of the survey, the lectures and exercises satisfied the students in the technical sense, such as the quality of video and audio signals, the usage of open platforms for e-Learning, etc. The main advantage mentioned in this survey is that video recordings of the lectures and exercises are available to the students at any moment in time. Also, some of the students think that they have better organization for their study time.

The main disadvantage detected is that during the online classes there is no "eye-toeye" contact with the lecturer. Also, $95 \%$ of the students find the lack of direct communication with other students as a main pitfall of online classes.

As a main disadvantage of the examination process, the students highlight the process of answering questions in the special formula editor. This process takes more time than answering with pen and paper. Also, some of them mention technical issues with their Internet connection during the exams.

Some interesting results were obtained for the question 8 of the survey. These are shown graphically in Fig. 6. As we can see, when students have problems with the material, most of them seek help either from a colleague, from a book, or from other online resources on the Internet.

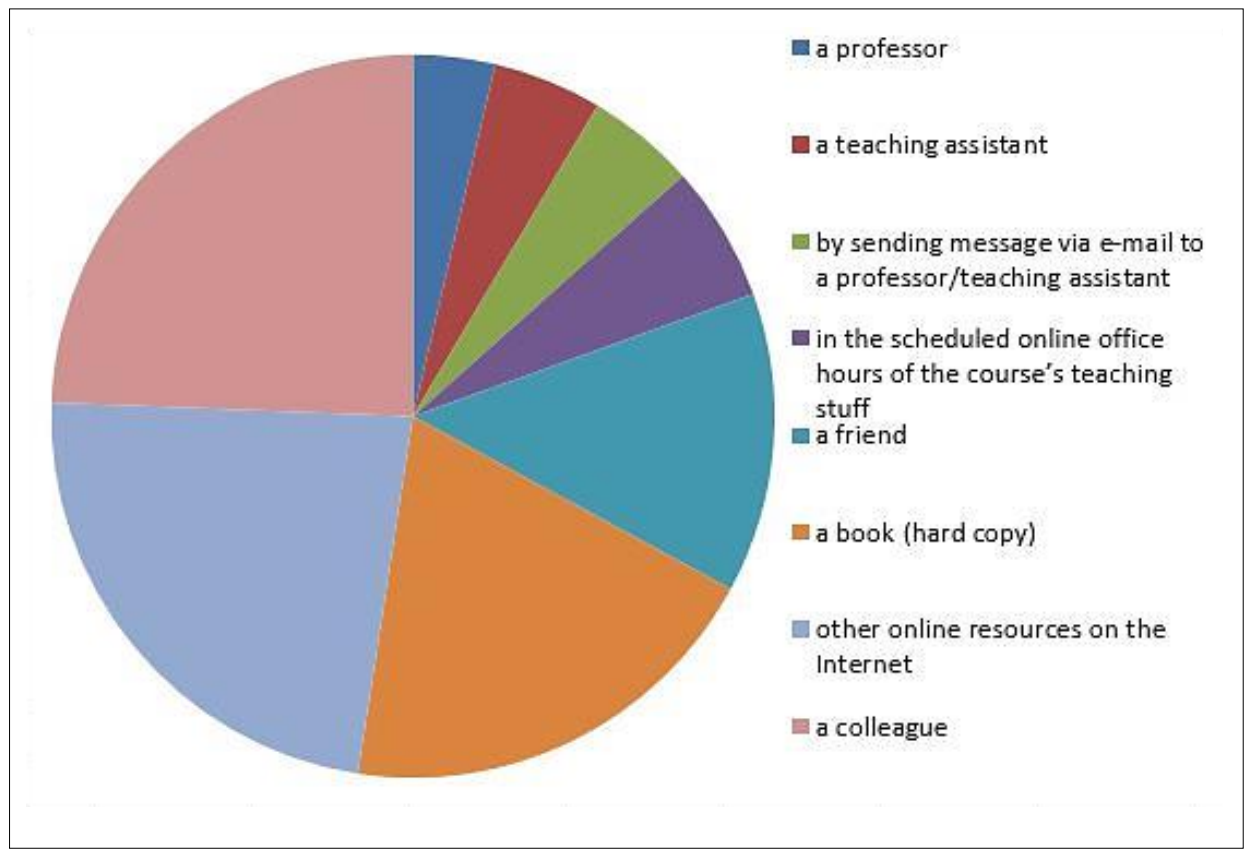

Fig. 6. Results for the question 8 of the survey on the Calculus 1 online classes. 


\section{Conclusion}

Overall, there is some increase in the percentage of students who have passed during the COVID-19 period, depending on the subject. The exception here is Calculus 2, where in 2018/2019 there was a newly accreditated program and there were no students retaking the exam, in contrast to $2019 / 2020$ where there were a significant number of students retaking the subject, which has a significant impact in the reduction of the passing rate of the colloquia and the first exam session.

The most lacking aspect of teaching during the corona crisis is the "eye-to-eye", or direct communication between the students themselves, as well as between the students and the teaching staff.

From the results of the survey, the lectures and exercises satisfied the students in the technical sense, such as the quality of video and audio signals, etc. The main advantage mentioned in this survey is that video recordings of the lectures and exercises are available to the students at any moment in time. Also, some of the students think that they have better organization for their study time.

The main disadvantage detected in the survey is that during the online classes there is no "eye-to-eye" contact with the lecturer. Also, 95\% of the students find the lack of direct communication with other students as a main pitfall of online classes.

The software and technical support that we have employed in the first year from the beginning of the corona crisis at FCSE, gave satisfactory results and experiences, which could be applied in the implementation of competitions in informatics, as well as other competitive disciplines. The emphasis from the experiences is on the online identification of the student, as well as the monitoring of his work for the entire task solving time.

Here we want to emphasize that one of the most important links in the success of the online exam conduction is the provision of technical support for a stable Internet connection during the examination process.

As the COVID-19 pandemic continues for a second year in a row, sharing our results in this study can help with more effective planning and choice of best practices to enhance the efficacy of online and distance education during COVID-19, as well as post-pandemic.

\section{Acknowledgement}

The research presented in this paper is partly supported by the Faculty of Computer Science and Engineering, at the Ss. Cyril and Methodius University in Skopje. 


\section{References}

Asgari, S., Trajkovic, J., Rahmani, M., Zhang, W., Lo, R. C., and Sciortino, A. (2021). An observational study of engineering online education during the COVID-19 pandemic. PLoS ONE 16(4): e250041.

Ballova Mikuskova, E., and Veresova, M. (2020). Distance education during Covid-19: the perspective of Slovak teachers. Problems of Education in the 21st century, 78(6), 884-906.

$\mathrm{BBB}$ - BigBlueButton, Open source virtual classroom software. https://bigbluebutton.org/ (accessed 16/5/2021)

Chan, R. Y., Bista, K., and Allen, R. M. (2021). Online Teaching and Learning in Higher Education during COVID-19: International Perspectives and Experiences, First Edition.

Courses - The course management system of the Faculty of Computer Science and Engineering, Ss. Cyril and Methodius University, Skopje.

https://courses.finki.ukim.mk/ (accessed 16/5/2021)

Dhawan, S. (2020). Online Learning: A Panacea in the Time of COVID-19 Crisis. Journal of Educational Technology Systems, 49(1), 5-22.

Exams - The exams management system of the Faculty of Computer Science and Engineering, Ss. Cyril and Methodius University, Skopje.

https://ispiti.finki.ukim.mk/ (accessed 16/5/2021)

GeoGebra - The mathematical software. https://www.geogebra.org (accessed 16/5/2021)

Pregowska, A., Masztalerz, K., Garlinska, M., and Osial, M. (2021). A Worldwide Journey through Distance Education-From the Post Office to Virtual, Augmented and Mixed Realities, and Education during the COVID-19 Pandemic. Educ. Sci. 2021, 11(3), 118.

WHO - World Health Organization. https: //www. who.int/ (accessed 16/5/2021)

Wolfram Mathematica: Modern Technical Computing. https: //www.wolfram.com/mathematica/ (accessed 16/5/2021)

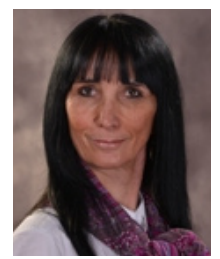

V.D. Ristovska is an associate professor at the Faculty of Computer Science and Engineering, Ss. Cyril and Methodius University, in Skopje. Her research interests include uniform distribution of sequences, numerical analysis, optimization methods, and topological data analysis.

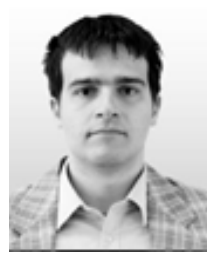

E. Stankov is a teaching and research assistant at the Faculty of Computer Science and Engineering, Ss. Cyril and Methodius University, in Skopje. He is a member of the Executive Board of the Computer Society of Macedonia and has actively participated in the organization and realization of the Macedonian national competitions and Olympiads in informatics since 2009. Currently he is a Ph.D. student at the Faculty of Computer Science and Engineering. His research includes analysis of program code correctness using different techniques, and its application to e-learning. 


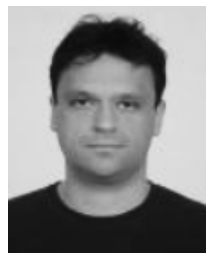

P. Sekuloski is a demonstrator (younger teaching and research assistant) at the Faculty of Computer Science and Engineering, Ss. Cyril and Methodius University, in Skopje. Currently he is a M.Sc. student at the Faculty of Computer Science and Engineering. His research includes Topological Data Analysis, Machine learning and application of some method from algebraic topology to computer science. 